Case Report

\title{
A CASE REPORT: ECTOPIC PREGNANCY DUE TO FAILURE OF EMERGENCY CONTRACEPTIVE
}

\author{
Arkierupaia Shadap \\ Lecturer, Department of Obstetrics \& Gynecological Nursing, Sikkim M anipal College of Nursing, \\ Sikkim Manipal University, Gangtok, Sikkim, India. \\ Correspondence : \\ Arkierupaia Shadap \\ Lecturer, Department of Obstetrics \& Gynecological Nursing, Sikkim Manipal College of Nursing, \\ Sikkim Manipal University, Gangotk, Sikkim - 737 102, India. \\ Mobile : +91 8116213637 E-mail : shadaparkierupaia@gmail.com
}

\begin{abstract}
:
An ectopic pregnancy is a pregnancy that develops outside the mother's womb when the fertilized egg from the ovary does not implant itself normally in the uterus. It is usually found in the first 5-10 weeks of pregnancy. To prevent unwanted pregnancy, emergency contraceptive used has been popular since the last two decades. It is seen to have $99 \%$ successful rate if taken within 72 hours after unprotected coitus and of which $1 \%$ is seen to have normal pregnancy or ecto pic pregnancy. Early diagnosisthrough thorough and detail history collection/ physical examination with early management has saved many maternal lives from unwanted risks, shocks, death etc.
\end{abstract}

Keywords: Ectopic, emergency contraceptive, human Chorionic gonadotrophin (HCG).

\section{Introduction:}

An ectopic pregnancy is one in which the fertilized ovum is implanted and develops outside the normal endometrial cavity. It contributes significantly to the cause of maternal mortality and morbidity. It has been seen that with increased incidence over the couples of decades, there has been a decline in the mortality rate. The recent improvement in the management of ectopic pregnancy is due to the recognition of high risk cases, early diagnosis(even before rupture) through the use of advent technology i.e; transvaginal ultrasonography(TVS), serum beta hCG and laparoscopy surgery. ${ }^{[1]}$

Extra-uterine and intra- uterine are the sites of ectopic implantation and of which the most commonly seen is tubal ectopic pregnancy which the extra-uterine site. The main causes of tubal ectopic pregnancy are due to the damage and dysfunction of the fallopian
Access this article online Quick Response Code

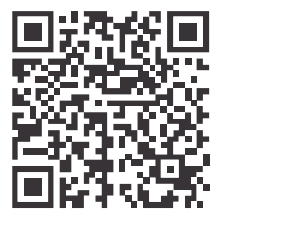
tubes, eg; tubal adhesion,

contraceptive methods. ${ }^{[2]}$

To avoid unwanted pregnancy after unprotected sexual intercourse, the new era (since two decades) has come up with the development of emergency contraceptives methods and the commonly used are;

- combined hormonal regime (Yuzpe method) in which two tablets of Ovral $(0.25 \mathrm{mg}$ levonorgestrel and 50 microgram ethinyl oestrdiol) to be taken within $72 \mathrm{hrs}$ after coitus and two more tablets to be taken $12 \mathrm{hrs}$ later.

- Levonorgestrel $0.75 \mathrm{mg}$ can be taken exclusively for 2 doses separated by 12-hours interval.

World Health Organization, Thaler shows that levonorgestrel efficacy was best when exclusively use than that of other emergency contraceptive methods available. ${ }^{[3][4]}$

The case report below occurred after the use of emergency contraceptive pills containing two tablets (1.50mg) levonorgestrel as single dose after 24 hours but within 72hours of unprotected sexual intercourse by woman who does not have risk factors for ectopic

in the tubal motility ismainly pregnancy.

due to the use of certain 


\section{A Case report:}

A patient came to the OPD ( $1^{\text {st }}$ visit) on the 15.01 .2013 with the complaint of missed period and on urine test at home (using preg- kit) it was found to be positive. Her last menstruation period was on the 12.12.2012. Through history collection it came to know that the patient took an emergency contraceptive after 48 hours of contact with her husband but within 72 hours. She has been married for more than six years and has a 5 years daughter.

On examination the patient's height is $152 \mathrm{~cm}$ and weight $47 \mathrm{kgs}$, vital signs were normal, no sign of pale and pallor, no history of any abortion or previous ectopic pregnancy and no complaint of abdominal pain or tenderness. According to her last menstrual period, her gestational age was almost 5 weeks (i.e; 4weeks 6days). Per vaginal examination was not done. On vaginal ultrasonography, it was found that the uterine endometrium lining was thick and cavity was empty. It was not clear so the doctor's advised her to come after 1week. A week after the patient again went for check-up ( $2^{\text {nd }}$ visit) and this time she came with the complaints of brownish discharge from the vagina. On examination through vaginal ultrasonography it was again found that the endometrium lining was thick, no reports of any gestational sac in the cavity and the doctor told that probably the brownish discharge must have been the implantation bleeding. It was also advised for serum beta hCG investigation and report shows it to be $3000 \mathrm{IU} / \mathrm{L}$. Still with these reports and findings the doctor advised the patient to come again after one more week because of the emptiness in the uterine cavity. The patient started showing stressful face and anxious looks, the concerned doctor counselled the patient not to worry and fixed date for the next week appointment. By the end of that week, the client gestation age has reached 7 weeks. On that third visit, still with the complaints of slight brownish thick discharge, vaginal ultrasonography was done. This time the uterine cavity still remains empty but a clear gestational sac with cardiac activity was seen on the left side of the fallopian tube. After a thorough vaginal ultrasonography it was diagnosed to be a left sided ectopic pregnancy with a positive cardiac activity.
The doctor's then explained the condition to the patient and that immediate intervention should be taken. The positive fetal cardiac activity in the fallopian tube has the risk of tubal rupture which may lead to many complications. So surgical removal of the ectopic was advised through laparoscopy. Pre-operative investigations was done and report shows serum beta hCG $=3900 \mathrm{IU} / \mathrm{L}$, haemoglobin $=12.4 \mathrm{mg} / \mathrm{dl}, \mathrm{A}+$ blood group. On the same day of diagnosed the ectopic pregnancy, emergency laparoscopic of left sided salpingectomy was done. The surgery was successful and condition of the patient improved day by day. The client then got discharge on the $7^{\text {th }}$ post-operative day with no complaints and stable vital signs.

\section{Discussion :}

Emergency contraceptive may be considered to be safe from unwanted pregnancies after unprotected intercourse as showed by many studies. Used of emergency contraceptives account for $75 \%$ reduction in the unwanted pregnancies. ${ }^{[9]}$. After the unprotected intercourse, it is seen that only $5.2 \%$ is the pregnancy rate, when emergency contraceptive is used correctly i.e; with 2 doses of $0.75 \mathrm{mg}$ levonorgestrel at a 12-hour interval, a maximum of 72 hours. ${ }^{[10]}$

Many studies reported the effectiveness of emergency contraceptive pills in lowering the risk of pregnancy and their use reduces the chance of ectopic pregnancy. But still, few women faced the danger of being diagnosed with ectopic pregnancy ${ }^{[5]}$.In fact, statistics supported the fact that women who took emergency contraceptives were less likely to have ectopic pregnancy simply because they were less likely to become pregnant.

The mechanisms of levonorgestrel is said to be multifactorial. It is seen that the progesterone drug level prevent the egg to move through the isthmus because of the relax tubal myoelectrical activity. As discussed above, changes in the motility of the tubes contribute to a delayed transportation of the egg from the tube to the endometrial cavity, which is a fact leading to the occurrence of ectopic pregnancy. ${ }^{[6][7]}$ 
It should be accentuated that the effectiveness of the emergency contraceptive pills/ treatment is said to be best and almost $100 \%$ when the drug is taken up to 24 hours after unprotected intercourse. It is seen that with the delayed and the increase in the time duration between the period of coitus and the beginning of treatment the efficacy is little low. It is because the mechanism of contraceptive action occurs mainly during fertilization and not during the period of blastocyst implantation. ${ }^{[8]}$

Report from literatures among women who does not have any identifiable risk factor for ectopic pregnancy believe the cause of ectopic pregnancy was due to unfertilized and fertilized ova which remains in the ampulla for almost 3days. ${ }^{[11]}$

\section{References}

1. Dutta's. D.C. Textbook of obstetrics. $7^{\text {th }}$ edition.

2. Cunningham FG, Gant NF, Leveno KJ, Gilstrap LC, Hauth JC, Wenstrom KD. Ectopic Pregnancy. In: Williams Obstetrics. 21st edition. M cGrawHill; 2001.

3. Thaler G. Collaboration with academia in the development of post ovulatory methods. International Journal of Gynaecology \& Obstetrics. 1999;67(Suppl 2):S77-83.

4. Task force on postovulatory methods of fertility regulation: World Health Organization. Randomised controlled trial of levonorgestrel versus the Yuzpe regimen of combined oral contraceptives for emergency contraception. Lancet. 1998;352:429-33.

5. Cleland K1, Raymond E, Trussell J, Cheng L, Zhu H. Ectopic pregnancy and emergency contraceptive pills: a systematic review. abstractabstractabstract202020abstract1false10bstet Gynecol. 2010 Jun;115(6):1263-6.

6. Liukko P, Erkkola R, Laakso L. Ectopic pregnancies during use of lowdose progestógenos for oral contraception. Contraception. 1977; $16: 575-80$.

7. Shoupe D, M ishell DR, Bradford L. The significance of bleeding patterns in Norplant users. Obstet Gynecol. 1991;77:256-62.

8. Faúndes A, Brache V, Alvarez F. Emergency contraception-clinical and ethical aspects. Int] Gynaecol Obstet. 2003,82:297-305.

9. Trussell J, Ellertson C, von Hertzen H. Estimating the effectiveness of emergency contraceptive pills. Contraception. 2003;67:259-65.

10. Wellbery C. Emergency contraception. Arch Fam M ed 2000; 9: 642-6.

11. Pereira, Cabar, Raiza, Roncaglia, Marcelo Zugaib. Emergency contraception and ectopic pregnancy: report of 2 cases. Clinics vol.60 no.6 São Paulo Dec. 2005

\section{Conclusion :}

Ectopic pregnancies are dangerous and it is still one of the leading causes of death among the reproductive age pregnancy, because of tubal rupture which may be due to late diagnosis and intervention. Ectopic pregnancies occur when the baby starts growing outside the uterus and this risk both the baby and the mother. Emergency contraceptives are believed to stop the pregnancy before it starts, which may be one cause of the pregnancy to be ectopic. So, early diagnosis for early management is very important so as to prevent rupture of the ectopic pregnancy and prevent death from shock and to reduce the maternal mortality rate in India. 